\title{
Foliar application of kaolin and zeolites to adapt the adverse effects of climate change in Vitis vinifera L. cv. Sangiovese
}

\author{
Gabriele Valentini ${ }^{*}$, Chiara Pastore $^{1}$, Gianluca Allegro ${ }^{1}$, Riccardo Mazzoleni ${ }^{1}$, Emilia Colucci $^{1}$, Ilaria Filippetti $^{1}$ \\ ${ }^{1}$ Dipartimento di Scienze e Tecnologie Agro-Alimentari (DISTAL), Viale Fanin, 46, 40127 (BO)
}

\begin{abstract}
One of the first effects of climate change in wine-growing areas is the advancement of phenological stages, especially concerning early berry ripening. In this condition, the decoupling between technological and phenolic maturity often occurs. Anthocyanins in red grapes are among the compounds that mostly contribute to phenolic maturity. However, their accumulation in the grape berries is known to be impaired by high temperatures. Therefore, this study aims to evaluate the efficacy of mineral-based compounds treatments with kaolin and zeolite, based on chabasite, on the enhancement of anthocyanins accumulation, also at the molecular level, analysing the gene expressions along the flavonoid biosynthesis pathway during ripening of Sangiovese berries. In addition, the temperature of berries and grape leaves, vine water status, leaf photosynthetic efficiency, total soluble solids, titratable acidity and $\mathrm{pH}$ were measured throughout the growing season. Hence, in the current study, it has been demonstrated the efficacy of kaolin and zeolite treatments not only in lowering the daily maximum grape berries temperature but also in the improvement of grapes anthocyanins accumulation correlated with the enhancement of expression of those genes involved in their biosynthesis pathway. Moreover, treatments had no significant effect on productive parameters.
\end{abstract}

\section{Introduction}

Climate change is undoubtedly harming viticulture, giving rise to severe changes in the grape-growing areas. Hence, in the current scenario of global warming, we are witnessing the advance of the grape's developmental stages and a consequent early ripening during the summer $[1,2]$, facing higher temperatures. It is well known that elevated temperatures have negative impacts on the colour of red grapevine varieties [3, 4], while water stress may also increase the anthocyanin concentration in the berry skins $[5,6]$. Generally, temperatures around $25^{\circ} \mathrm{C}$ promote anthocyanins biosynthesis, whereas high temperatures, such as $35^{\circ} \mathrm{C}$ or above, are associated with their degradation [7]. Besides, Movahed et al. (2016) have reported that high temperatures suppressed the biosynthesis of anthocyanins to both the transcriptional and enzymatic levels, probably due to higher peroxidase activity [8]. Heatwaves during the ripening may also induce a rapid soluble solids accumulation, paralleled with faster depletion of organic acid, an increase of $\mathrm{pH}$ and undesired aroma compounds [9]. Therefore, the resulting wines are less susceptible to ageing, have poor colour, and altered aromatic profiles [10]. Thus, the concept of phenolic maturity comes to be important, as it is referred not only to proper phenols content but also to their different composition and extractability. According to the latest OIV (International Organization of Vine and Wine) report [11], Italy was rated as the top world wine producer with 47.2 million hectoliters, and Sangiovese represented Italy's top variety, the only one whose cultivation exceeded 50,000 hectares [12]. It is known that Sangiovese berries skin has a low concentration of anthocyanins [13]. Besides, Mattivi et al. (2006) showed that the average anthocyanins concentration in Sangiovese berries is much lower in comparison with the more widespread Cabernet Sauvignon cultivar [14]. The challenge of berries colour that growers are coping with within warmer regions is progressively becoming more complex and, given the circumstances of ongoing climate change, might have severe consequences on grapes quality-parameter contents, such as anthocyanins. Accordingly, researchers have focused on finding a proper solution to mitigate these phenomena in the past decades $[15,16]$. With this purpose, new short-term agronomic techniques are now available, such as postveraison shoot trimming or apical leaf removal [17-19], smart irrigation $[20,21]$ and foliar application of particle materials, such as kaolin and zeolite [22, 9]. As regards the latter, kaolin, $\mathrm{Al}_{2} \mathrm{Si}_{2} \mathrm{O}_{5}(\mathrm{OH})_{4}$, is a phyllosilicate white mineral that, once applied to the leaves, reflects potentially damaging ultraviolet and infrared radiation and transmits photosynthetically active radiation, resulting in leaf temperature decrease and photosynthetic efficiency increase [23]. Thanks to these features, its canopy implementation has been largely studied. In grapevine, it has been demonstrated how kaolin application enhanced cooler canopy temperatures, low stomatal conductance under non-limiting soil moisture conditions, protection of photosystem II structure and the

*corresponding author: gabriele.valentini4@,unibo.it 
increase in total anthocyanin, also at the molecular level. [24-29]. On the other hand, zeolite-group minerals are aluminium silicates of the alkali and alkaline earth elements with open-framework structures of linked ( $\mathrm{Si}$, $\mathrm{Al}) \mathrm{O}_{4}$ tetrahedra [30] and due to their crystalline structure, the high cation exchange capacity, and the ability to retain water, zeolites are increasingly used in agriculture [31]. Recent research has demonstrated how treatments with kaolin and natural zeolite around veraison can positively affect physiological parameters and enhance anthocyanins concentration in grape berries and the final wines $[22,9]$. This study aims to evaluate the efficacy of treatments with kaolin (CAO) and zeolite (ZEO) on the enhancement of anthocyanins accumulation also at the molecular level, analysing the gene expressions along the flavonoid biosynthesis pathway during ripening in Sangiovese berries.

\section{Materials and methods}

\subsection{Plants material and experimental design}

The experimental design included 135 vines distributed in three randomized blocks along the rows. Each block consisted of 45 vines distributed in three treatments: C, untreated control vines sprayed with water; $\mathrm{CAO}$, kaolin sprayed treatment; ZEO, natural Italian chabasite-rich zeolitites sprayed treatment. The solutions of kaolin and zeolite with chabasite were prepared at $3 \%$ and sprays, together with control with water, were carried out on July the 29th (DOY 210, 1st treatment) and on August the 7th (DOY 219, 2nd treatment) in 2019. Throughout the ripening phase, 7 samplings were carried out in different moments (T) to perform technological ripening evaluations, anthocyanins analysis via HPLC and gene expression analysis via Real Time-PCR (Table 1).

Table 1: Berries samplings carried out during the ripening phase in 2019 , in the period from the $29^{\text {th }}$ of July to harvest $(H)$, on the $26^{\text {th }}$ of September.

\begin{tabular}{|c|c|}
\hline T & Timing of berries samplings \\
\hline T0 & Preceding first treatment (DOY 210) \\
\hline T1 & 48 hours after the first treatment (DOY 212) \\
\hline T2 & Preceding the second treatment (DOY 219) \\
\hline T3 & 48 hours after the second treatment (DOY 221) \\
\hline T4 & 2 weeks after the second treatment (DOY 232) \\
\hline T5 & 4 weeks after the second treatment (DOY 247) \\
\hline H & (DOY 269) \\
\hline
\end{tabular}

\subsection{Microclimate measurements}

The weather conditions were recorded by a meteorological station located nearby the experimental vineyard and equipped with a rain gauge, thermocouples and relative humidity sensors (iFarming Srl, Ravenna, RA, IT). Grape berries temperature was monitored during the whole trial period using 8 thermocouples per treatment
(Spectrum Technologies Inc, Aurora, IL, USA) inserted under the berries skin. The selected berries were included in clusters located on the East and West side and inside the canopy, taking into consideration the North-South oriented row. An IR-20 infrared thermometer (Raytek Raynger ST., Santa Cruz, California, USA) was used to assess leaf temperatures. Leaf temperature measurements were taken on three well-exposed leaves per vine and were carried out on DOY 213, DOY 221 and DOY 225 in all three treatments.

\subsection{Water status and leaf gas exchange measurements}

Midday stem water potential $\left(\Psi_{\text {stem }}\right)$ was measured on fifteen vines per treatment using a Scholander-type pressure chamber (Model 3005, Soil Moisture Equipment Corp., Santa Barbara, CA, USA), at midday on a mature leaf per vine on DOY 213, DOY 221 and DOY 225. Leaf net assimilation $\left(\mathrm{A}_{\mathrm{n}}\right)$ and stomatal conductance $\left(\mathrm{g}_{\mathrm{s}}\right)$ rates were measured using a portable gas exchange Li-Cor 6400 system (Li-Cor Inc., Lincoln Nebraska, USA). Measurements were taken on fifteen leaves per treatment.

\subsection{Vine growth, yield components, and berry composition}

At harvest (26 $6^{\text {th }}$ September, DOY 269), the production of each vine under test was recorded by detecting the number of grape bunches and the total weight. Moreover, at harvest, 50 berries per vine were collected and crushed. The must obtained was sieved and used for soluble solid analysis using a temperature-compensating CR50 refractometer (Maselli Misure Spa, Parma, Italy). A sample of $5 \mathrm{ml}$ of the same must was then diluted seven times with bi-distilled water for titration using a Crison Compact Titrator (Crison, Barcelona, Spain) with $0.25 \mathrm{~N}$ $\mathrm{NaOH}$ (Sigma-Aldrich, St. Louis, MO, USA) to obtain $\mathrm{pH}$ and titratable acidity data (expressed as $\mathrm{gL}^{-1}$ of tartaric acid equivalents). Total anthocyanins were analyzed by collecting 20 berries per vine and soaking the peeled skins

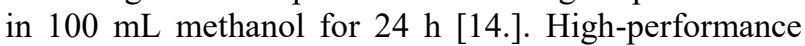
liquid chromatography (HPLC) separation and quantification of anthocyanins were performed on a Waters 1525 HPLC (Waters, Milford, MA, USA) equipped with a diode array detector (DAD) and a Phenomenex (Castel Maggiore, Bologna, Italy) reversedphase column $(\mathrm{RP} 18,250 \mathrm{~mm} \times 4 \mathrm{~mm}, 5 \mu \mathrm{M})$. The anthocyanins were quantified at $520 \mathrm{~nm}$ using an external calibration curve with malvidin-3-glucoside chloride as the standard (Sigma-Aldrich, St Louis, MO, USA), following the procedure reported by Mattivi et al. (2006).

\subsection{Molecular analysis}

In compliance with the analysis purposes, the grape skin tissues were picked and grounded in powder to perform RNA extraction, following the protocol listed on the Spectrum $^{\mathrm{TM}}$ Total RNA Kit manual. To establish the total RNA purity and concentration, ratios between the absorbance 260/280 and 260/230 were detected through a 
spectrophotometer Nanodrop ND-1000 (ThermoScientific, Wilmington, DE). The RNA samples $(1 \mu \mathrm{g})$ were then retro-transcribed into cDNA through the reverse transcriptase reaction, carried out with the ImPromII ${ }^{\mathrm{TM}}$ Reverse Transcriptase enzyme (Promega Corporation, Madison, USA). Real-time qPCR analysis was then executed with an ABI PRISM StepOnePlus system (Applied Biosystems, Foster City, CA, USA) to evaluate the efficacy of treatments with kaolin $(\mathrm{CAO})$ and zeolites (ZEO) and control plants (C) on the enhancement of anthocyanins accumulation at the molecular level. Following the reference literature, was taken into consideration the expression of 3 different genes along the biosynthesis pathway of anthocyanins (PAL1, MYBA 1, UFGT) and 2 (ACT, UBQ) as an internal control [32-34].

\subsection{Statistical analysis}

Statistical analysis was carried out using SAS statistical package V9.0 (SAS Institute, Cary, NC, USA). The difference among average data was assessed using the Tukey statistical analysis test $(\mathrm{p} \leq 0.05)$. The Real-Time qPCR efficiencies were calculated using the LinRegPCR program. Afterwards, the outcoming data were processed to transform means of raw data Cycle-Threshold (CT) values and the related standard errors (SEs) into means of normalized expression (MNE) levels and their respective SEs, following the protocol presented by Simon (2003) [35].

\section{Results and discussion}

\subsection{Environmental conditions, leaf and berry temperatures}

The 2019 monthly average weather parameters measured from April to October from the weather station located in the experimental vineyard are reported in Table 2.

Considering that the mean growing season temperature (April-October) is $20.4^{\circ} \mathrm{C}, 2019$ can be considered as a warm year according to the value of $18.49^{\circ} \mathrm{C}$ reported by Teslic et al., (2018) [36] and referred to 60 years period for Emilia Romagna region.

Table 2: Monthly mean air temperature, rainfall and air relative humidity recorded for the growth period (Apr-Oct 2019) at a weather station close to the vineyard.

\begin{tabular}{|c|c|c|c|}
\hline & DOY 213 & DOY 221 & DOY 225 \\
\hline $\mathrm{C}$ & $33.2 \mathrm{a}$ & $32.9 \mathrm{a}$ & $31.0 \mathrm{a}$ \\
\hline CAO & $32.6 \mathrm{~b}$ & $31.0 \mathrm{~b}$ & $29.9 \mathrm{~b}$ \\
\hline ZEO & $32.2 \mathrm{~b}$ & $31.2 \mathrm{~b}$ & $30.3 \mathrm{~b}$ \\
\hline
\end{tabular}

Thermal readings taken on the leaves (Table 3) showed that the CAO and ZEO treatments had discordant effects on the canopy cooling in comparison with $\mathrm{C}$.

Besides, the minerals distributed on the foliage caused a significant drop in the leaf temperatures which lasted over time. Such cooling effect was further confirmed by the trend of grape berries temperature (Figure 1).

Table 3: Single leaf temperatures $\left({ }^{\circ} \mathrm{C}\right)$ measured using an infrared thermometer in 2019. Different letters within a column indicate significant differences as calculated using the Tukey statistical analysis test $(\mathrm{p} \leq 0.05)$.

\begin{tabular}{|c|c|c|c|}
\hline & $\begin{array}{c}\mathrm{T} \\
\left({ }^{\circ} \mathrm{C}\right)\end{array}$ & $\begin{array}{c}\text { Rainfall } \\
(\mathrm{mm})\end{array}$ & $\begin{array}{c}\text { Relative humidity } \\
(\%)\end{array}$ \\
\hline April & 14.3 & 53.6 & 67.1 \\
\hline May & 15.2 & 185.5 & 74.6 \\
\hline June & 25.2 & 24.4 & 57.1 \\
\hline July & 25.8 & 30.2 & 61.5 \\
\hline August & 25.6 & 30.5 & 65 \\
\hline September & 20.4 & 48.9 & 69.7 \\
\hline October & 16.6 & 45 & 80.7 \\
\hline
\end{tabular}

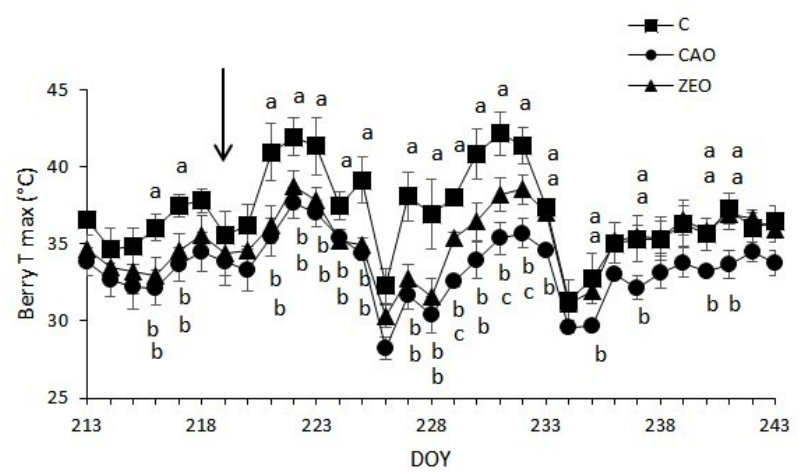

Fig. 1: Trend of daily maximum berry temperature $\left({ }^{\circ} \mathrm{C}\right)$ measured using thermal probes in August 2019. The values are presented as mean \pm standard error (SE) $(n=8$ per treatment). Different letters indicate significant differences between treatments according to the Tukey test $(p \leq 0.05)$. The arrow indicates the date of the second treatment with the mineral particles.

Therefore, it has been demonstrated that treatment with kaolin and zeolite chabasite can reduce the grape cluster temperature, with a remarkable effect especially during the warmest days of the season, when the berry temperature in $\mathrm{C}$ overcome $40^{\circ} \mathrm{C}$. Particularly, kaolin treatment led to grape cluster temperature for most of the trial period below $35^{\circ} \mathrm{C}$, which has been identified in Sangiovese as a critical threshold value, above which might occur severe consequences in the accumulation of anthocyanins [4].

\subsection{Vine water status and leaf gas exchange}

The meteorological conditions, as well as the treatments, did not affect the vines water status as shown from midday stem water potential data reported in Table 4.

As shown in Table 5, CAO treatment significantly reduced the leaf assimilation rate (An) on DOY 213, two days after the first implementation, while gas exchange (gs) was significantly affected on DOY 221, two days after the second foliar application (DOY 219). It is well- 
known that, under optimal water conditions, kaolin usually decreases the assimilation rate (An), probably because of shading and stomatal limitation effects $[9,37$, 38] unlike zeolite which maintains a high photosynthetic performance throughout the season [39].

Table 4: Midday stem water potential ( $\Psi_{\text {stem, bar }}$ during 2019. Different letters within a column indicate significant differences by the Tukey statistical analysis test $(p \leq 0.05)$.

\begin{tabular}{|c|c|c|c|}
\hline & DOY 213 & DOY 221 & DOY 225 \\
\hline $\mathrm{C}$ & $-4.3 \mathrm{a}$ & $-4.1 \mathrm{a}$ & $-4.1 \mathrm{a}$ \\
\hline CAO & $-5.6 \mathrm{a}$ & $-3.9 \mathrm{a}$ & $-3.9 \mathrm{a}$ \\
\hline ZEO & $-5.4 \mathrm{a}$ & $-3.8 \mathrm{a}$ & $-5.2 \mathrm{a}$ \\
\hline
\end{tabular}

Table 5: Leaf stomatal conductance $\left(\mathrm{g}_{\mathrm{s}}, \mathrm{mol} \mathrm{m}^{-2} \mathrm{~s}^{-1}\right)$ and leaf

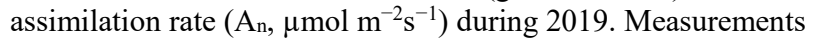
were taken on three well-exposed leaves per vine. Different letters within a column indicate significant differences as calculated by the Tukey statistical analysis test $(\mathrm{p} \leq 0.05)$.

\begin{tabular}{|c|c|c|c|c|c|c|}
\hline \multirow{2}{*}{} & \multicolumn{2}{|c|}{ DOY 213} & \multicolumn{2}{c|}{ DOY 221} & \multicolumn{2}{c|}{ DOY 225} \\
\cline { 2 - 7 } & gs & An & gs & An & gs & An \\
\hline C & $0.17 \mathrm{a}$ & $23.4 \mathrm{a}$ & $0.23 \mathrm{a}$ & $17.5 \mathrm{a}$ & $0.21 \mathrm{a}$ & $17.1 \mathrm{a}$ \\
\hline CAO & $0.17 \mathrm{a}$ & $15.3 \mathrm{~b}$ & $0.19 \mathrm{~b}$ & $15.3 \mathrm{a}$ & $0.22 \mathrm{a}$ & $16.4 \mathrm{a}$ \\
\hline ZEO & $0.18 \mathrm{a}$ & $21.6 \mathrm{a}$ & $0.28 \mathrm{a}$ & $19.4 \mathrm{a}$ & $0.26 \mathrm{a}$ & $15.0 \mathrm{a}$ \\
\hline
\end{tabular}

\subsection{Vine growth, yield components, and fruit composition at harvest}

No significant differences were reported among treatments in terms of yield components (yield per vine, weight of the bunch, or berry mass), soluble solids and $\mathrm{pH}$. However, CAO showed a higher titratable acidity as compared to $\mathrm{C}$ and ZEO (Table 6), which might be hypothetically associated with the greater effect of kaolin in cooling grapes temperature and consequently preserving the malic acid degradation.

Table 6. Yield parameter and fruit components recorded in Sangiovese vines undergoing kaolin (CAO) and chabasite-rich zeolitite (ZEO) treatments and the control (C) vines in 2019. Different letters in a column for a given year indicate significant differences after the Tukey statistical analysis test $(\mathrm{p} \leq 0.05)$.

\begin{tabular}{|l|c|c|c|}
\hline & $\mathrm{C}$ & CAO & ZEO \\
\hline Yield per vine $(\mathrm{kg})$ & $5.82 \mathrm{a}$ & $5.36 \mathrm{a}$ & $5.46 \mathrm{a}$ \\
\hline Bunch weight $(\mathrm{g})$ & $338 \mathrm{a}$ & $317 \mathrm{a}$ & $327 \mathrm{a}$ \\
\hline Berry mass $(\mathrm{g})$ & $2.54 \mathrm{a}$ & $2.54 \mathrm{a}$ & $2.42 \mathrm{a}$ \\
\hline $\begin{array}{l}\text { Soluble solids } \\
\left({ }^{\circ} \text { Brix }\right)\end{array}$ & $20.0 \mathrm{a}$ & $20.6 \mathrm{a}$ & $20.7 \mathrm{a}$ \\
\hline $\mathrm{pH}$ & $3.5 \mathrm{a}$ & $3.4 \mathrm{a}$ & $3.4 \mathrm{a}$ \\
\hline $\begin{array}{l}\text { Titratable acidity } \\
(\mathrm{g} / \mathrm{L})\end{array}$ & $6.84 \mathrm{~b}$ & $7.22 \mathrm{a}$ & $6.65 \mathrm{~b}$ \\
\hline
\end{tabular}

CAO treatment favoured anthocyanins accumulation throughout the ripening, expressed as $\mathrm{mg} / \mathrm{g}$ of berry skin, in comparison with $\mathrm{C}$ (Figure 2).

Kaolin treatment appeared to have a significant effect on the enhancement of anthocyanins accumulation in two distinct moments of ripening: after veraison and at harvest. Anyway, all along with the ripening, both kaolin and zeolites tendentially favoured the anthocyanins accumulation rather than the control treatment, confirming what was already described by Calzarano et al. (2019) [4].

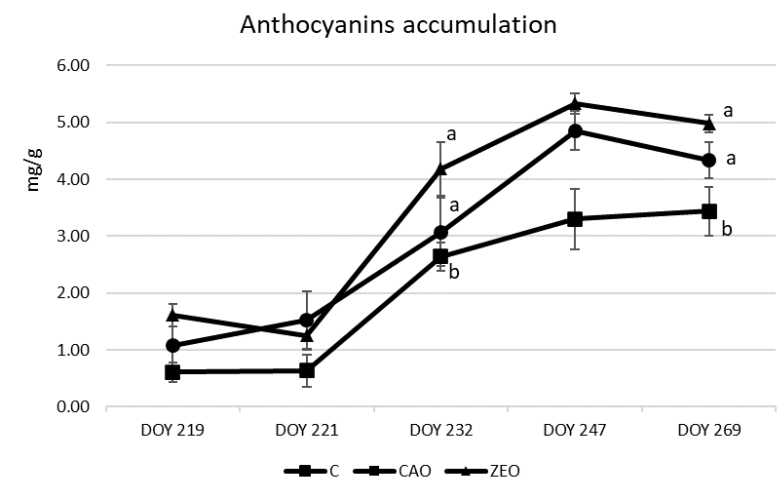

Fig. 2. Evolution of anthocyanins concentration, measured in $\mathrm{mg} / \mathrm{g}$ of grape skin, across the ripening.

\subsection{Anthocyanins biosynthesis gene expression}

Significant statistical differences were observed among the three treatments in the expression of PAL1 (Figure 3), MYBA1 (Figure 4) and UFGT (Figure 5).

PAL1, coding for the enzyme phenylalanine ammonium-lyase in the initial stages of flavonoids biosynthesis, resulted higher expressed in correspondence with the implementation of CAO and ZEO, with a remarkable effect for zeolite just 48 hours after the first application. This result reinforces what was demonstrated by Conde et al. (2016), that higher PAL1 gene expression indicates strong evidence of a final increase in the synthesis of anthocyanins compounds. The transcription factor MYBA1, which triggers the UFGT gene in the final reactions preceding the anthocyanins formation, was significantly higher expressed, likewise PAL1, in concurrence with the implementation of the treatments, again with a notable effect for zeolite. UFGT, which glycosylates anthocyanidins into anthocyanins using UDP-glucose as co-substrate, is the key enzyme of the anthocyanin biosynthesis in grapevine. The gene was indeed more expressed especially in berries from zeolite treatments, with a very good correlation with increased UFGT expression and increased anthocyanin concentration.

The molecular analysis exhibited a diversified peculiar mechanism of action among the two minerals. Zeolite might promptly accelerate the enhancement of key genes expression in the anthocyanin's biosynthesis while kaolin might have a putative substantial stronger impact in reducing the temperature on both canopy and grape berries improving microclimate conditions and leading to 
the achievement of optimal conditions for anthocyanin biosynthesis.

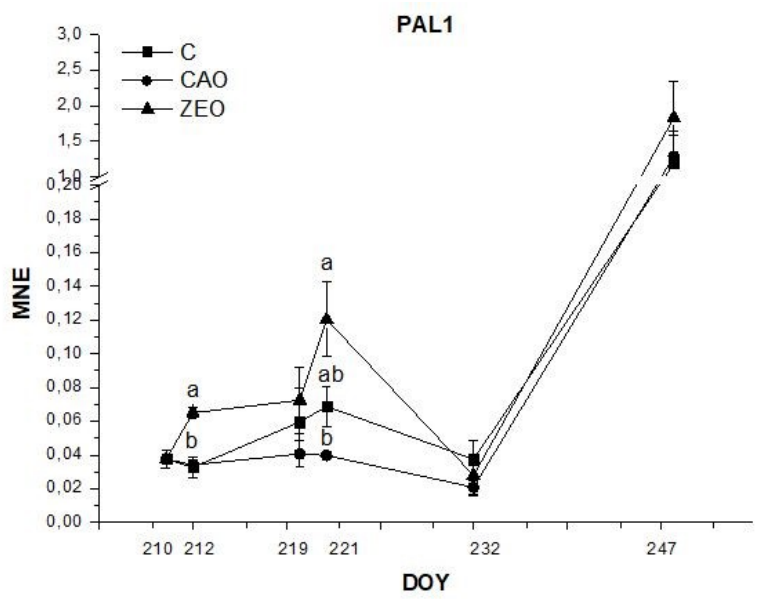

Fig. 3. PAL1 (phenylalanine ammonium lyase) expression throughout the ripening in 2019.

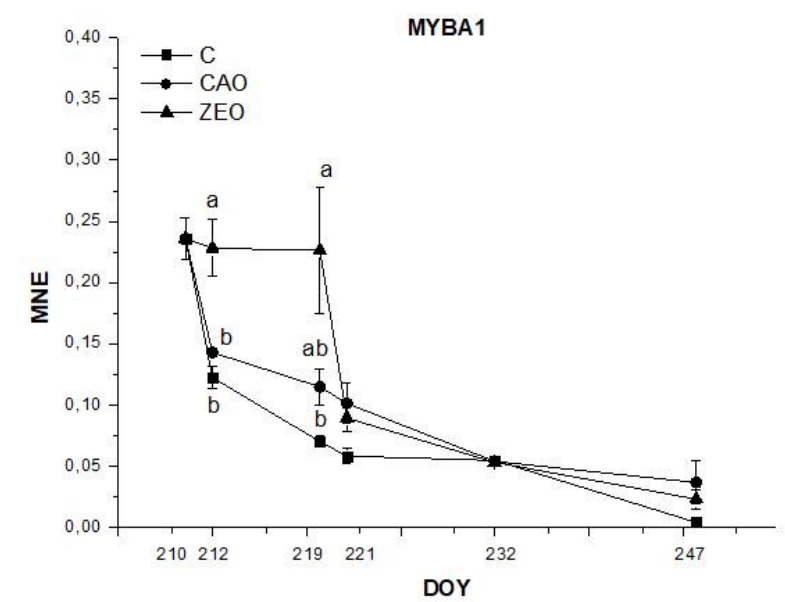

Fig. 4. MYBA1 transcription factor expression throughout the ripening in 2019.

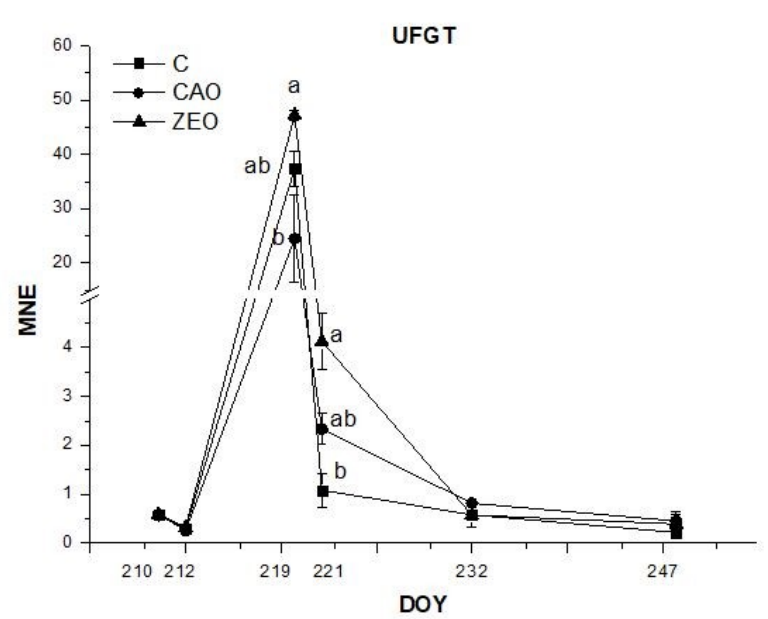

Fig. 5. UFGT (UDP-glucose flavonoid 3-Oglucosyltransferase) expression throughout the ripening in 2019.

\section{References}

1. G. V. Jones, M. A. White, O. R. Cooper, \& K. Storchmann. Clim. Change, 73 (3), 319-343, (2005).

2. E. Duchêne. OENO One, 50 (3), (2016).

3. K. Mori, N. Goto-Yamamoto, M. Kitayama, \& K. Hashizume. J. Exp. Bot., 58 (8), 1935-1945, (2007).

4. C. Pastore, S. Dal Santo, Zenoni, N. Movahed, G. Allegro, G. Valentini, \& G. B. Tornielli. Front. Plant. Sci., 8, 929, (2017).

5. M. M. Chaves, T. P. Santos, C. R. Souza, M. F. Ortuno, M. L. Rodrigues, C. M. Lopes, J. P. Maroco, J. S. Pereira. Ann. Appl. Biol., 150, 237-252, (2007).

6. V. Lanari, A. Palliotti, P. Sabbatini, G. S. Howell, O. Silvestroni. Sci. Hortic. 179, 239-247, (2014).

7. F. He, L. Mu, G.-L. Yan, N.-N. Liang, Q.-H. Pan, J. Wang, M. J. Reeves, C.-Q. Molecules, 15, 90579091, (2010).

8. N. Movahed, C. Pastore, A. Cellini, G. Allegro, G. Valentini, S. Zenoni, E. Cavallini, E. D'Incà, G. B. Tornielli, I. Filippetti. J. Plant Res., 129 (3), 513-526, (2016).

9. G. Valentini, C. Pastore, G. Allegro, E. Muzzi, L. Seghetti, I. Filippetti. Agronomy, 11, (2021).

10. A. Palliotti, S. Tombesi, O. Silvestroni, V. Lanari, M. Gatti, S. Poni. Sci. Hort. 178, 43-54, (2014).

11. OIV. Statistical Report on World Vitiviniculture OIV first estimates. International Organization of Vine and Wine, (Paris, France 2020).

12. OIV. Distribution of the World's Grapevine Varieties. International Organization of Vine and Wine, (Paris, France 2017).

13. J. A. Santos, H. Fraga, A. C. Malheiro, J. MoutinhoPereira, L.-T. Dinis, C. Correia, M. Moriondo. Appl. Sci. 10, 3092, (2020).

14. F. Mattivi, R. Guzzon, U. Vrhovsek, M. Stefanini, R. Velasco. J. Agric. Food Chem., 54, 7692-7702, (2006).

15. H. Fraga, A. C. Malheiro, J. Moutinho-Pereira, J. A. Santos. Food Energy Secur., 94-110, (2012).

16. L. Hannah, P. R. Roehrdanz, M. Ikegami, A. V. Shepard, M. R. Shaw, G. Tabor. Clim. Change, PNAS U.S.A., 110, 6907-6912, (2013).

17. I. Filippetti, N. Movahed, G. Allegro, G. Valentini, C. Pastore, E. Colucci, C. Intrieri. Aust. J. Grape Wine Res., 21, 90-100, (2015).

18. G. Valentini, G. Allegro, C. Pastore, E. Colucci, I. Filippetti. J. Sci. Food Agric., 99, 1358-1365, (2019).

19. A. Palliotti, F. Panara, O. Silvestroni, V. Lanari, P. Sabbatini, G. S. Howell, M. Gatti, S. Poni. Aust. J. Grape Wine Res., 19, 369-377, (2013a).

20. H. Fraga, I. García de Cortázar Atauri, J. A. Santos. Agric. Water Manag. 196, 66-74, (2018).

21. J. M. Costa, M. Vaz, J. Escalona, R. Egipto, C. Lopes, H. Medrano, \& M.M. Chaves. Agric. Water Manag., 164, 5-18, (2016). 
22. F. Calzarano, G. Valentini, G. Arfelli, L. Seghetti, A. C. Manetta, E. G. Metruccio, S. Di Marco. Phytopathol. Mediterr., 58 (2), 307-321, (2019).

23. D. M. Glenn \& G. J. Puterka. Hort. Rev., 31, 1-44, (2005).

24. K. Shellie \& D. M. Glenn. Hort. Science, 43, 13921397, (2008).

25. D. M. Glenn, N. Cooley, R. Walker, P. Clingeleffer, K. Shellie. Hort. Science, 45, 1178-1187, (2010).

26. J. Song, K. C. Shellie, H. Wang, M. C. Qian. Food Chem., 841-850, (2012).

27. L. T. Dinis, S. Bernardo, A. Conde, D. Pimentel, H. Ferreira, L. Félix. J. Plant Physiol., (2016a).

28. T. Frioni, S. Tombesi, E. Luciani, P. Sabbatini, J. G. Berrios, A. Palliotti. Kaolin treatments on Pinot noir grapevines for the control of heat stress damages. BIO Web of Conferences, 13, 04004. EDP Sciences, (2019).

29. A. Conde, D. Pimentel, A. Neves, L. Dinis, S. Bernardo, C. Correia, H. Geros, J. Moutinho-Pereira. Front. Plant Sci., 7, 1150, (2016).

30. R. A. Deer, W.A. Howie, W.S. Wise, J. Zussman. Rock-Forming Minerals. Framework Silicates: Silica Minerals, Feldspathoids and Zeolites, London, UK, 2nd ed. The Geological Society, (2004).

31. D.W. Minge, E.R. Allen. Nat. Zeolites, 45, 619-654, (2001).

32. J. Bogs, M. O. Downey, J. S. Harvey, A. R. Ashton, G. J. Tanner, S. P. Robinson. Plant Phy., 139 (2), 652-663, (2005).

33. S. T. Jeong, N. Goto-Yamamoto, S. Kobayashi, M. Esaka. Plant Sci., 167 (2), 247-252, (2004).

34. N. Goto-Yamamoto, G. H. Wan, S. Kobayashi. Acta Hort., 603, 571-579, (2003).

35. P. Simon. Q-Gene: processing quantitative real-time RT-PCR data. Bioinformatics, application note, vol. 19, 1439-1440. (2003).

36. N. Teslić, G. Zinzani, G. P. Parpinello, et al. Theor. Appl. Climatol. 131, 793-803, (2018).

37. V. Cantore, B. Pace, R. Albrizio. Environ. Exp. Bot., 66, 279-288, (2009).

38. F. Boari, A. Donadio, M. I. Schiattone, V. Cantore. Agric. Water Manag., 47, 154-162, (2015).

39. C. De Smedt, K. Steppe, P. Spanoghe. Adv. Mater. Sci., 2, 1-11, (2017). 